\title{
Detection of Potential ESBL, Ampc, and Metallo-Beta- Lactamase Producers (MDR-GNB) Through In-vitro Susceptibility Testing of Genitourinary Specimens in a Community-based Pilot Study
}

\author{
Dina Abed ${ }^{1}$, Ammar Jusmani $^{2}$, Sinan Alrifai ${ }^{3, *}$ \\ ${ }^{1}$ Dept. of Gynecology \& Obstetrics, Ibn Sina University of Medical and Pharmaceutical Sciences, Iraq, Baghdad \\ ${ }^{2}$ Dept. of Basic Sciences, Ibn Sina University of Medical and Pharmaceutical Sciences, Iraq, Baghdad \\ ${ }^{3}$ Ibn Sina University of Medical and Pharmaceutical Sciences, Iraq, Baghdad \\ *Corresponding author. Email: sinanbahjat@ibnsina.edu.iq
}

\begin{abstract}
This is a pilot study, which is intended to represent a basis for future studies pertinent to multidrug-resistant antimicrobial gram-negative (MDR-GNB) bacteria that commonly prevail in Iraqi community and hospital settings. In the present study, we scrutinize the antimicrobial phenotypic resistant patterns of commonly isolated Enterobacteriaceae (i.e., E. coli, E. aerogenes, $K$. oxytoca, $P$. mirabilis) from urine, wound samples, and high vaginal swabs in the Iraqi community. One hundred fifty- six (156) urine, genital lesions, and high vaginal swab samples were obtained from a community population in a cross-sectional study held in Baghdad at a private Lab from December 2020 to the end of April 2021. These specimens were isolated and identified according to conventional methods. Antimicrobial sensitivity tests were done according to the Kirby-Bauer method, and interpretation of results was made with reference to CLSI Standards for Antimicrobial Susceptibility Testing. Gram-negative bacilli were isolated from 80 (about $51 \%$ ) of genitourinary specimens sent to the laboratory for culture and sensitivity. E. coli and E. aerogenes showed the most frequent bacterial isolate in genitourinary samples (60\% and $31.25 \%$, respectively). Complete resistance (i.e. 100\%) to Amoxicillin-Clavulanic acid and Cefotaxime and high resistance (i.e. 97.5\%) to Cefixime, Ceftriaxone, and Ceftazidime by these bacterial strains were observed. Assessment of Enterobacteriaceae antibiotic resistance for both of $\beta$ - lactams and Carbapenems showed that $25 \%$ of these strains were having resistance to both groups of antibiotics. As a conclusion; Enterobacteriaceae multi-drug resistance reflects potential ESBL, Ampc, and carbapenemase activity in Iraq.
\end{abstract}

Keywords: MDR-GNB, genitourinary, antibiotic susceptibility.

\section{INTRODUCTION}

Multi-drug resistant gram-negative- bacteria (MDRGNB) prevalence is on the rise worldwide [1] and has left a negative impact on the quality of health-care, which is clear from healthcare- associated infections (HAI) as in surgical site infections (SSI) in various categories of patients and hospitals [2]. This stands in clear contrast to prior studies where some surgical site infections revealed a poly-microbial picture [3]. Such a situation resulted from resistant mechanisms intrinsic to gram-negative bacteria [1]. It follows that bacterial genetic machinery led to emergence of Beta-lactamase hydrolytic enzyme activity in what is now known as (ESBL), (AmpC), (Carbapenemase) [4,5], the latter was first detected in a Swedish tourist in 2009 New Delhi, India, hence its 
designated name (NDM-1) [6-8], however, it should be noted that an Escherichia coli strains in patients with no travel history to the Indian subcontinent had been isolated and was suspected to be (NDM-1) when it demonstrated non-susceptibility to Carbapenem and third-generation antimicrobials [9].

The NDM-1 can be conveyed to human intestinal normal flora, further compounding the problem [10], and in connection to these antibiotics prescribed for humans can change the overall natural inhabitants of human intestinal flora [11,12]. The accumulative effects of the aforementioned environmental and health factors along with the emergence of other Carbapenem-resistant gramnegative bacteria such as the non- fermentative Carbapenem- resistant Pseudomonas aeruginosa (CRPA) [13] in the ICU led to a desperate search for solutions to the challenge of treating (MDR-GNB). The aim of the current study is to explore a preliminary assessment of multi-drug resistant (MDR) Enterobacteriaceae in clinical samples of the genitourinary system in women living in Baghdad, Iraq.

\section{MATERIALS AND METHODS}

A cross-sectional, community- based study was held in Baghdad / Private clinic from December 2020 to the end of April 2021 were 156 different specimens from genito-urinary system including urine, vaginal lesions, and genital wound swabs from patients suffered from symptoms and signs of different bacterial infections were enrolled for the detection of Enterobacteriaceae in these specimens and assessing their antibiotic resistance pattern.

Midstream-urine clean catch samples (MSU) were obtained in sterile containers from individuals in the community. Wound (from the genitourinary system) and high vaginal swabs were aseptically taken with non-toxic sterile cotton swabs. All specimens were inoculated according to conventional methods [16-20].

Anti-microbial susceptibility tests were run for the bacterial isolates according to the Kirby-Bauer method. Results were interpreted according to clinical and laboratory standards institutes (CLSI) Performance Standards for Antimicrobial Susceptibility Testing [21].

The ethical approval for current study was obtained from the Institutional Review Board (IRB) at Ibn Sina University of Medical and Pharmaceutical Sciences, Baghdad, IRAQ. Patient's informed consent was obtained from all the patients for using their samples in the current study. The authors declare that they have no conflict of interest associated with this publication.

\section{RESULTS}

Among 156 specimens sent for culture and sensitivity to the laboratory, gram-negative bacilli were isolated from 80 (about $51 \%$ ) of them- that were identified later as Enterobacteriaceae "Table (1)".

The frequency of bacterial isolates occurrence in specimens is shown in "Figure (1)", E. coli shows the most frequent bacterial isolate in vaginal and urine samples $(70 \%$ and $66.6 \%$, respectively), while $E$. aerogenes showed the most frequent isolate among vaginal swab samples $(56.6 \%)$ in the current study.

The proportion of resistance for these bacterial isolates to common B-lactams and Carbapenems used in Iraq is shown in "Table (2)".

Enterobacteriaceae antibiotic resistance for B- lactams and for both of $\beta$ - lactams and Carbapenems is demonstrated in "Figure (2)".

\section{DISCUSSION}

The observed results in this pilot study can be dichotomized on the basis of statistical results and the community setting as the source of bacterial samples in relation to documented observations. The phenotypic antimicrobial sensitivity tests reveal a resistant pattern of Enterobacteriaceae which are clear against the third generation cephalosporins with $100 \%$ antibiotic resistance to Amoxicillin-Clavulanic acid and Cefotaxime. Other 3rd generation cephalosporins showed also a high resistance pattern (i.e. 97.5\%). These readings can be accounted for on the basis of the hydrolytic enzyme activity of the Enterobacteriaceae microorganisms against extended spectrum cephalosporins to which the above mentioned isolates are non-susceptible. Basically bacterial enzymatic hydrolysis is brought about through extended spectrum-Betalactamase (ESBL) activity and $(\mathrm{AmpC})$ production $[4,5]$. Several bacteria of the Enterobacteriaceae group do possess extended spectrum-Beta-lactamase [22] activity which explains their resistant pattern against the third generation antimicrobials.

Our antibiogram demonstrates about $15 \%$ resistance to Imipenem. Moreover, about $22.5 \%$ of resistance against another Carbapenem antimicrobial was noticed, namely meropenem. This is due to metallo-beta lactamase (MBL) enzyme production in these resistant strains [23].

The NDM-1 is another plasmid-mediated transmissible carbapenemase gene, which readily spreads among bacterial populations and has gained much 
attention recently given the nature of protective hydrolytic activity of Beta-lactamase in this lethal strain that overcomes bactericidal effects of B-lactams. Hence the term metallo-Beta-lactamase applies to (NDM-1) (MDR) strain possessing a lethal nature capable of acquiring additional resistant genes [23] which is evidently clear from the antimicrobial sensitivity test results in current study. The potential presence of (NDM1) bacterial strain isolates in this study cannot be discounted given that many Iraqi citizens have in recent years travelled to the Indian subcontinent to seek medical consultation and even subjected to surgical procedures [4].

It therefore becomes necessary to run lab based confirmatory tests to pick up (ESBL) producing gram negative strains [22,24,25]. In future Iraqi labs. implementing antimicrobial tests for resistant strains may face limitations in terms of (PCR) genotyping of (MDRGNB) suspected of having (NDM-1) and other resistant genes. For the time being, and probably in the imminent future, treatment of infections in general will be based on phenotypic antibiograms and bacterial species identification.

\section{CONCLUSIONS}

Enterobacteriaceae multi-drug resistant bacteria isolated from genitourinary tract in current study reflects potential ESBL, Ampc, and carbapenemase activity.

\section{FIGURES AND TABLES}

Table 1. Type of isolated Enterobacteriaceae from genitourinary samples

\begin{tabular}{|c|c|c|c|c|c|c|}
\hline$\frac{\frac{0}{0}}{\frac{\varepsilon}{\sqrt{0}}}$ & í & 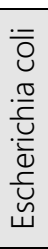 & 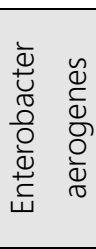 & 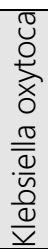 & 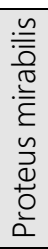 & 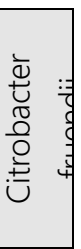 \\
\hline $\begin{array}{l}\bar{D} \\
\stackrel{\bar{E}}{D} \\
\stackrel{D}{>}\end{array}$ & 21 & 14 & 5 & 1 & 1 & 0 \\
\hline$\stackrel{\stackrel{\oplus}{\frac{.}{5}}}{\supset}$ & 42 & 26 & 11 & 3 & 1 & 1 \\
\hline $\begin{array}{l}0 \\
\stackrel{0}{5} \\
0 \\
3\end{array}$ & 17 & 8 & 9 & 0 & 0 & 0 \\
\hline
\end{tabular}
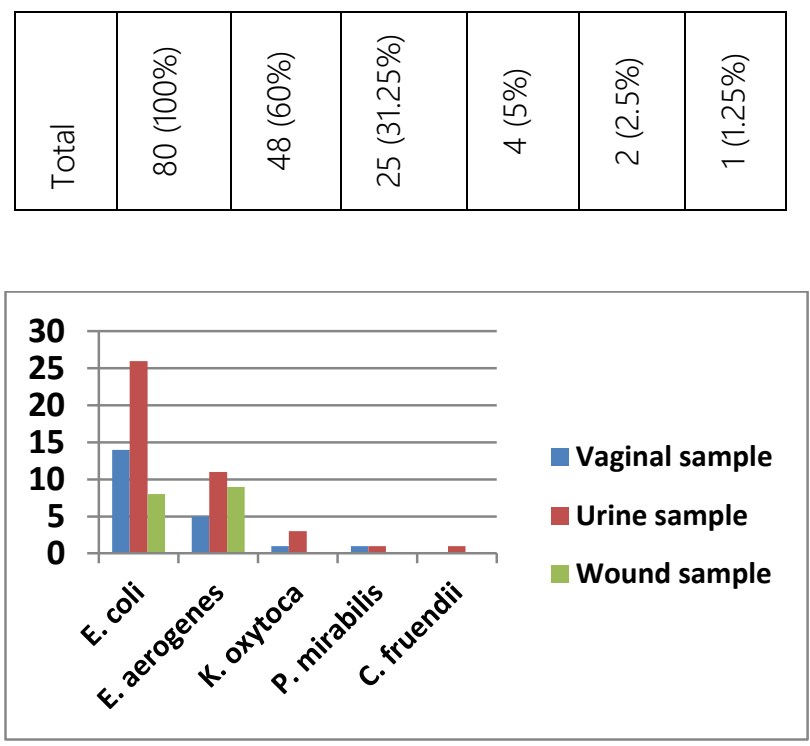

\begin{tabular}{|c|c|c|c|c|c|}
\hline $\begin{array}{l}\text { Anti- } \\
\text { biotic } \\
\text { * }\end{array}$ & $\begin{array}{l}\text { No. of } \\
\text { sensitive } \\
\text { strains } \\
(n=80)\end{array}$ & $\%$ & $\begin{array}{l}\text { No. of } \\
\text { resistant } \\
\text { strains } \\
(n=80)\end{array}$ & $\%$ & $\begin{array}{l}95 \% \\
\text { Confid- } \\
\text { ence } \\
\text { interval }\end{array}$ \\
\hline $\begin{array}{l}\text { Amx/ } \\
\text { Clv }\end{array}$ & 0 & $0 \%$ & 80 & $\begin{array}{c}100 \\
\%\end{array}$ & $\begin{array}{l}0.0000 \\
\text { to } \\
0.0451\end{array}$ \\
\hline CTX & 0 & $0 \%$ & 80 & $\begin{array}{c}100 \\
\%\end{array}$ & $\begin{array}{l}0.0000 \\
\text { to } \\
0.0451\end{array}$ \\
\hline CRO & 2 & $\begin{array}{c}2.5 \\
\%\end{array}$ & 78 & $\begin{array}{c}97.5 \\
\%\end{array}$ & $\begin{array}{l}0.0030 \\
\text { to } \\
0.0874\end{array}$ \\
\hline CFM & 2 & $\begin{array}{c}2.5 \\
\%\end{array}$ & 78 & $\begin{array}{c}97.5 \\
\%\end{array}$ & $\begin{array}{l}0.0030 \\
\text { to } \\
0.0874\end{array}$ \\
\hline CFZ & 2 & $\begin{array}{c}2.5 \\
\%\end{array}$ & 78 & $\begin{array}{c}97.5 \\
\%\end{array}$ & $\begin{array}{l}0.0030 \\
\text { to } \\
0.0874\end{array}$ \\
\hline MEM & 62 & $\begin{array}{c}77.5 \\
\%\end{array}$ & 18 & $\begin{array}{c}22.5 \\
\%\end{array}$ & $\begin{array}{l}0.6679 \\
\text { to } \\
0.8609\end{array}$ \\
\hline IMI & 68 & $85 \%$ & 12 & $15 \%$ & $\begin{array}{l}0.7526 \\
\text { to } \\
0.9200\end{array}$ \\
\hline \multicolumn{6}{|c|}{$\begin{array}{l}\text { *Amx/Clv= Amoxicillin/Clavulanic acid, CTX= } \\
\text { Cefotaxime, CRO= Ceftriaxone, } \mathrm{CFM}=\text { Cefixime, } \mathrm{CFZ=} \\
\text { Ceftazidime, } \mathrm{MEM}=\text { Meropenem, IMI=Imipenem }\end{array}$} \\
\hline
\end{tabular}

Figure 1. Frequency of bacterial isolates occurrence in genitourinary specimens 
Table 2. Resistance of Enterobacteriaceae to common ßlactams and Carbapenems used in Iraq

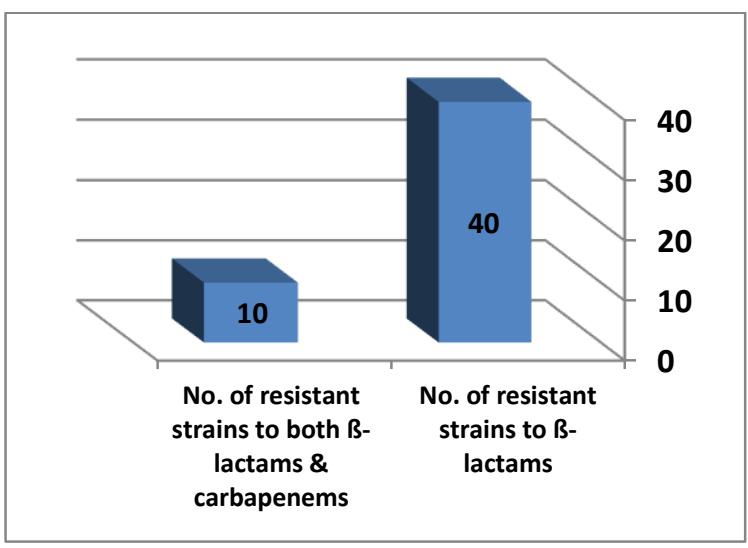

Figure 2. No. of Enterobacteriaceae strain with antibiotic resistance for ß- lactams and for both of ß- lactams \& Carbapenems.

\section{AUTHORS' CONTRIBUTION}

Author DA selects the clinical cases and made the primary diagnosis, sent samples to the laboratory, and design the study. Authors AJ and SA made the laboratory diagnosis including isolation and identification of the bacteria, write the initial manuscript, and make the statistical analyses. All authors have read the full manuscript and participate in writing the final manuscript.

\section{ACKNOWLEDGMENT}

We would like to acknowledge the staff of "AlBariq Specialized Laboratory" for providing necessary help during collection of samples and their help for providing necessary tools and materials for the final isolation and identification of bacteria.

\section{REFERENCES}

[1] B. Li, T.J. Webster, Bacteria Antibiotic Resistance: New Challenges and opportunities for ImplantAssociated Orthopedic Infections. Journal of Orthopedic Research 36 (1) (2018) 22-32.

[2] J.C. Hernaiz-Leonardo, M.F. Golzarri, P. CorneoJuarez, et al., Microbiology of Surgical Site Infections in Patients with Cancer/ A7-year review. American Journal of Infection and Control, vol 1, 45(7) (2017) 761-766.
[3] A. Abdul Jabbar, S.H. Berven, S.S. HU, et al., Surgical Site Infections in Spine Surgery: identification of microbiological and surgical characteristics in 239 cases. Spine (phila pa 1976). 38(22) (2013) e1425-1431.

[4] S-S Jean and P-R Hsueh, Distribution of ESBLs, AmpC B-lactamases and carbapenemases among Enterobacteriaecae isolates causing intra-abdominal and urinary tract infections in the Asia-Pacific region during 2008-14. Journal of Antimicrobial Chemotherapy 72(1) (2017) 166-171.

[5] G.A. Jacoby, AmpC B-lacatmases. Clinical Microbiology Reviews (2009) 161-182.

[6] D. Raghunath. New Metallo B-lactamase NDM-1. Indian Journal of Medical Researches 132(5) (2010) $478-481$

[7] R.C. Moellering, NDM-1- A Cause for Worldwide Concern. New England Journal of Med 363(25) (2010) 2377-9.

[8] A J. Brink, J. Coetzee, C.G. Clay, et al. Emergence of New Delhi Metallo-Beta-Lactamase (NDM-1) and Klebsiella pneumonia Carbapenemase (KPC-2) in South Africa. Journal of Clinical Microbiology 50(2) (2012) 525-527.

[9] L. Geneviev, P. Buser, M. Cassidy, C.D. Pfieffer, et al., New Delhi metallo-B-lactamase-1 (NDM-1) Escherihia coli isolated from household vacuum cleaner Oregon, 2013. ScienceDirect ID cases June, 15(9) (2017) 56-58. Doi: 10.1016/j.idcr 2017.06.00

[10] L. Ye, E.W. Chi Chan and S. Chen, Selective and suppressive effects of antibiotics on donor and recipient bacterial strains in gut microbiota determine transmission efficiency of blaNDM-1bearing plasmids. Journal of Antimicrobial Chemotherapy 74(7) (2019) 1867-1875.

[11] N. Kieffer, J. Guzman-Puche, L. Poirel, et al., An itrisic MBL from the environmental gram negative speciesZhongshaniaaliphaticivorans. Journal of Antimicrobial Chemotherapy 74(6) (2019) 15681571 .

[12] J. Wang, X. Yao, J. Luo, et al., Emergence of Escherichia coli co-producing NDM-1 and KPC-2 carbapenemases from a retail vegetable, China Journal of Antimirobial Chemotherapy 73(1) (2018) 252-254.

[13] M. Coppry, C. Jeanne-Leroyer, P. Noize, C. Dumartin, et al., Antibiotics associated with acquisition of carbapenem-resistant Pseudomonas aeruginosa in ICUs: a multicentre nested case-casecontrol study. Journal of Antimicrobial Chemotherapy 74(2) (2019) 503-510. 
[14] J.H. Kwon, M.K. Fausone, H. Du, A. Robicsek, et al., Impact of laboratory-reported urine culture colony counts on the diagnosis and treatment of urinary tract infection for hospitalized patientsNCBI- NIH. American Journal of Clinical Pathology 137(5) (2012) 778-784.

[15] M. Franz, W.H. Horl, Common errors in diagnosis and management of urinary tract infection. In: Pathophysiology and diagnostic techniques, Nephrology Dialysis Transplantation, volume 14, issue 11, 1999, pp. 2746-2753.

[16] K.B. Roberts and E.R. Wald, The Diagnosis of UTI: Colony Count Criteria Revisisted. Pediatrics 141(2) (2018) e20173239.

[17] G.J. Wise and P.N. Schlegel, Sterile Pyuria. New England Journal of Medicine 372 (2015) 1048-1054.

[18] R. Mazhari and P.L. Kimmel, Hematuria: An algorithmic approach to finding the cause. Clevland Clinic Journal of Medicine 69(11) (2002) 870, 872$884,879-884$.

[19] A. O. Alfred, O. Matie, S.A. Gbenga, et al, Diagnostic Characteristics of Urine Microscopy in Detecting Asymptomatic Bacteriuria of Pregnancy Using Urine Culture as Gold Standard. Journal of Dental and Medical Sciences (IOSR-JDMS) 13(1) (2014) 87-90.

[20] J.J. Farmer, B.R. Davis, H. Brenner, et al, Biochemical identification of new species and biogroups of Enterobacteriaecae isolated from clinical specimens. Journal of Clinical Microbiology. 21(1) (1985) 46-76.

[21] CLSI. Performance Standards for AntimicrobialSusceptibility Testing. $28^{\text {th }}$ ed. CLSI supplement M100. Wayne, PA: Clinical and Laboratory Standards Institute (2018).

[22] K.S. Thomson. Extended- Spectrum-B-Lactamase, AmpC, and Carbapenemase issues. Journal of Clinical Microbiology 48(4) (2010) 1019-1025.

[23] J.W. Rasmussen and N. Hoiby. Class A Carbapenemases. Journal of Antimicrobial Chemotherapy 60(3) (2007) 470-482.

[24] B. Zheng, H. Zhu, X. Yu, et al., Identification and genomic characterization of A KPC-2-NDM-1- and NDM-5-producing Klebsiella michiganensis isolate. Journal of Antimicrobial Chemotherapy 73(2) (2018) 536-538.

[25] C.E. Ali, S.A. Anwar, S.B. Issa, et al., Study of Urinary tract infection among pregnant women in Kirkuk. Tikrit Medical Journal 13(2) (2007) 39-43. 